Rochmawati, Sri Hayuningsih, Estu Lovita Pembayun, Veronica Fary, Arini Kusmintarti, Liana Elfaristo, Kasyafiya Jayanti, Gracea Petricka, Sisilia Prima

\title{
PELAYANAN KEPADA MASYARAKAT MELALUI PEMERIKSAAN GULA DARAH PADA LANSIA DI PRAKTIK BIDAN BERSAMA CITRA LESTARI KECAMATAN BOJONGGEDE KABUPATEN BOGOR
}

\author{
Rochmawati $^{1}$, Sri Hayuningsih ${ }^{2}$, Estu Lovita Pembayun ${ }^{3}$, Veronica Fary ${ }^{4}$, \\ Arini Kusmintarti ${ }^{5}$, Liana Elfaristo ${ }^{6}$, Kasyafiya Jayanti ${ }^{7}$, Gracea Petricka ${ }^{8}$, \\ Sisilia Prima9
}

Universitas Gundarma (Program Studi Kebidanan, Universitas Gunadarma), Jl. Raya Bogor KM 31 No.28-30 Cisalak Pasar, 16452

Email : ramadhan.rochmawati@staff.gunadarma.ac.id

\begin{abstract}
ABSTRAK
Penyakit Diabetes merupakan salah satu penyebab terjadinya penyakit ginjal dan kebutaan serta amputasi yang bukan disebabkan karena disabilitas pada populasi berusia di bawah 65 tahun. Berdasarkan hasil wawancara awal dengan mitra, diperoleh informasi bahwa masih banyak lansia yang tidak memeriksakan kesehatannya terutama pemeriksaan gula darah. Mitra kegiatan pengabdian masyarakat ini yaitu Praktik Bidan Bersama Citra Lestari yang bertempat di Kp. Pos Citayam RT. 02/RW.11 No. 14 Kel. Pabuaran, Kec. Bojonggede, Kab. Bogor. Diusia yang sudah lanjut dan penurunan fungsi tubuh akan membawa dampak yang kurang baik bagi lansia terutama mengenai kesehatan dirinya. Tujuan kegiatan pengabdian masyarakat ini yaitu melakukan kegiatan pemeriksaan gula darah pada lansia. Tahap pertama kegiatan ini adalah menyiapkan bahan dan alat yang akan digunakan untuk pemeriksaan gula darah. Tahap berikutnya adalah pelaksanaan kegiatan pemeriksaan gula darah. Kegiatan pemeriksaan gula darah pada 16 Oktober 2020 berlangsung selama kurang lebih 1 jam melibatkan 18 orang lanjut usia yang berdomisili di wilayah sekitar tempat Praktik Bidan Bersama Citra Lestari. Kegiatan dilaksanakan secara door to door untuk menghindari kerumunan, serta mengikuti protokol kesehatan yang dianjurkan pemerintah karena kegiatan ini dilaksanakan di masa pandemi COVID-19. Berdasarkan pemeriksaan yang dilakukan didapatkan hasil pemeriksaan terdapat 3 (tiga) orang lansia yang memiliki kadar gula darah diatas batas maksimal yang dianjurkan, dan sebanyak 15 (lima belas) orang lainnya memiliki kadar gula darah dibawah batas maksimal yang dianjurkan.
\end{abstract}

Kata kunci: Pemeriksaan gula darah, lansia, COVID-19

\section{ABSTRACT}

Diabetes is one of the causes of kidney disease and blindness and amputation not caused by disabilities in the population under 65 years of age. Based on the results of initial interviews with partners, information has been obtained that there are still many elderly people who do not have their health checked, especially blood sugar control. The partner of this community service is the Citra Lestari Joint Midwife Practice, which is located at Kp. Pos Citayam RT. 02 / RW.11 no. 14 Ex. Pabuaran, Kec. Bojonggede, Kab. Bogor. Old age and impaired body function have an adverse effect on the elderly, especially on their own health. The purpose of this community service is to control blood sugar in the elderly. The first phase of this activity is to prepare materials and 
tools that will be used for blood sugar testing. The next stage is the implementation of blood sugar control. The blood sugar check on October 16, 2020 took approximately 1 hour involving 18 elderly people living in the area around the Citra Lestari Joint Midwife Practice. The activity was conducted door to door to avoid crowds and to follow health protocols recommended by the government as this activity was conducted during the COVID-19 pandemic. Based on the study, it was determined that 3 (three) elderly people had a blood sugar level above the recommended maximum limit and as many as 15 (fifteen) others had a blood sugar level below the recommended maximum limit.

Keywords: Blood sugar control, the elderly, COVID-19

\section{PENDAHULUAN}

Diabetes Melitus (DM) adalah suatu penyakit kronis yang disebabkan karena organ Pankreas dalam tubuh tidak dapat berfungsi dengan baik dalam menghasilkan Insulin yang cukup bagi tubuh, atau ketika tubuh tidak dapat menggunakan Insulin secara efektif sebagaimana seharusnya (WHO, 2016). Studi juga menunjukkan bahwa Diabetes dapat mengurangi usia harapan hidup 5-10 tahun.

Usia harapan hidup penderita DM tipe 2 yang mengidap penyakit mental serius seperti Skizofrenia bahkan memiliki usia harapan hidup yang lebih rendah lagi, 20\% lebih rendah bila dibandingkan dengan populasi umum (Goldberg 2007 dalam Garnita 2012). Berdasarkan data yang diperoleh pada tahun 2018 penderita DM paling banyak berada pada kelompok rentang usia 55-64 tahun dan antara 65-74 tahun (Riskesdas, 2018).

Dampak DM dan komplikasinya sangat terasa baik bagi individu, keluarga, maupun negara. Kerugian ekonomi dapat dirasakan baik secara langsung melalui biaya medis yang mahal, kehilangan penghasilan karena diberhentikan dari pekerjaan akibat penyakitnya sehingga menyebabkan individu menjadi kurang produktif. Selain biaya perawatan rumah sakit yang mahal, biaya rawat jalan seperti pemeriksaan dan penyediaan Insulin bagi penderita DM secara berkala juga membutuhkan biaya yang tidak sedikit (Pusdatin, 2018).

Oleh karena itu Prodi Kebidanan Universitas Gunadarma merasa perlu memperhatikan kebutuhan kelompok usia lanjut sebagai salah satu kelompok risiko penderita DM di tengah pandemi ketika segala sesuatu dibatasi sedemikian rupa demi mencegah penyebaran Covid-19. Termasuk juga akses ke fasilitas pelayanan kesehatan sehingga menyebabkan beberapa aktifitas pelayanan kesehatan yang seharusnya rutin dilakukan tidak dapat diakses untuk sementara waktu. Situasi dan keadaan ini tentunya perlu mendapatkan perhatian, jangan sampai ditengah akses yang terbatas ini justru menyebabkan kadar gula darah kurang terpantau dengan baik. 
Rochmawati, Sri Hayuningsih, Estu Lovita Pembayun, Veronica Fary, Arini Kusmintarti, Liana Elfaristo, Kasyafiya Jayanti, Gracea Petricka, Sisilia Prima

\section{MASALAH}

Permasalahan yang paling utama yang dihadapi oleh Mitra yaitu banyak lanjut usia yang belum melakukan pemeriksaan gula darahnya. Berdasarkan analisis permasalahan tersebut, Program Studi Kebidanan Universitas Gunadarma, melalui program pengabdian kepada masyarakat bermaksud memberikan kontribusi sesuai dengan bidang keilmuan yang dimiliki yakni dengan melakukan pemeriksaan gula darah terlebih lagi dimasa pandemik COVID-19. Situasi saat ini membuat kita harus tetap menjaga jarak serta memperhatikan kesehatan, untuk itu kegiatan pemeriksaan gula darah dilakukan melalui door to door bekerjasama dengan Praktik Bidan Bersama Citra Lestari, Kec.Bojonggede, Kab.Bogor.

\section{METODE}

Pemeriksaan gula darah pada lansia melalui door to door dilakukan tanpa adanya biaya sebagai wujud pelaksanaan pengabdian masyarakat (Abdimas) dari tim dosen Program Studi Kebidanan Universitas Gunadarma, Mahasiswa Kebidanan bekerjasama dengan Praktik Bidan Bersama Citra Lestari, Kec.Bojonggede, Kab.Bogor. Metode yang digunakan sebagai pendekatan pelaksanaan pengabdian masyarakat adalah pemeriksaan gula darah lansia di masa pandemi Covid-19. Adapun rangkaian kegiatan pengabdian masyarakat, dimulai dari analisis kebutuhan (kebutuhan periksa gula darah lansia), menentukan desain strategi pemeriksaan kesehatan, melakukan informed consent (pemeriksaan hanya dilakukan bagi lansia yang bersedia diperiksa), melakukan pemeriksaan pemeriksaan gula darah dengan memperhatikan protokol kesehatan, menyajikan hasil pemeriksaan gula darah.

Bahan-bahan pemeriksaan gula darah pada kegiatan pengabdian masyarakat ini meliputi bahan utama dan bahan pendukung. Bahan utama dalam pelaksanaan kegiatan adalah alat monitor kadar gula darah/ Glukometer, Stik gula darah, handscone, alkohol swab, bengkok, lanset, pen lanset. Bahan-bahan pendukung pelaksanaan kegiatan meliputi handsanitizer, pulpen, buku catatan.

Adapun metode pelaksanaan program penelitian dan pengabdian masyarakat ini, yaitu dimulai dari langkah berikut :

1. Melakukan koordinasi dengan pihak terkait

2. Melakukan sosialisasi awal kegiatan pengabdian masyarakat

3. Melakukan analisis kebutuhan mitra

4. Melakukan persiapan pelaksanaan pemeriksaan gula darah

5. Melaksanaan pemeriksaan gula darah dengan memperhatikan protokol kesehatan sebagai upaya pencegahan penyebaran Covid-19.

6. Melakukan penyusunan laporan kegiatan dan menyusun publikasi pada media masa cetak

7. Menyerahkan laporan kegiatan Pengabdian Kepada Masyarakat.

\section{HASIL DAN PEMBAHASAN}

Kegiatan pemeriksaan gula darah pada 16 Oktober 2020 berlangsung selama kurang lebih 1 jam melibatkan 18 orang lanjut usia yang berdomisili di 
wilayah sekitar tempat Praktik Bidan Bersama Citra Lestari. Kegiatan dilaksanakan secara door to door untuk menghindari kerumunan, karena kegiatan ini dilaksanakan di masa pandemi COVID-19.

Berdasarkan pemeriksaan yang dilakukan didapatkan hasil pemeriksaan terdapat 3 (tiga) orang lansia yang memiliki kadar gula darah diatas batas maksimal yang dianjurkan, dan sebanyak 15 (lima belas) orang lainnya memiliki kadar gula darah dibawah batas maksimal yang dianjurkan.
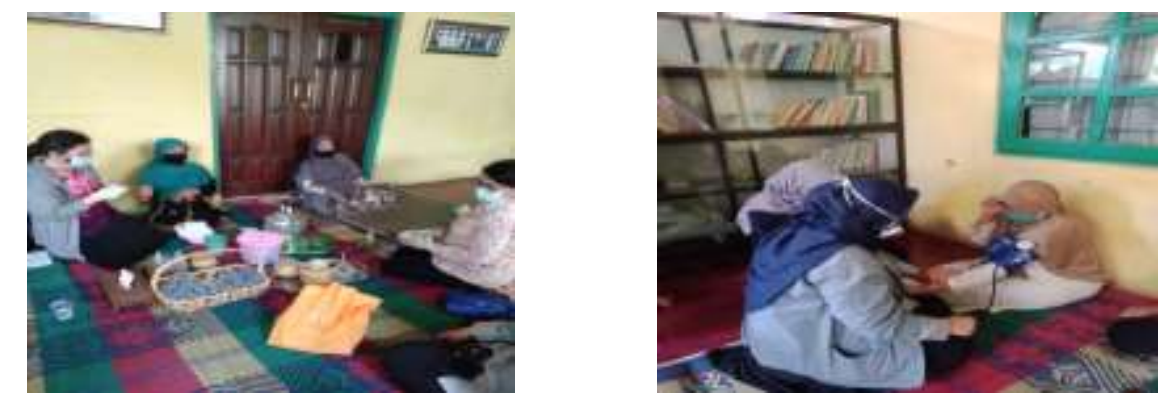

Sehingga dapat dikatakan telah berhasil dilakukan pemeriksaan kesehatan berupa pemeriksaan gula darah sehingga meningkatkan kesehatan dan kesadaran bagi para lansia untuk rajin memeriksanan kesehatan dirinya, terutama bagi para lansia yang memiliki kadar gula darah yang tinggi agar tetap terpantau dan terukur.

Tahapan berikutnya dalam kegiatan penelitian dan pengabdian masyarakat ini adalah melakukan pemeriksaan ulang sebagai upaya monitoring secara berkala serta memberikan advokasi kesehatan kepada lansia dan keluarganya mengenai Diabetes Melitus serta pemeriksaan gula darah secara mandiri dengan tujuan terus membangun dan meningkatkan kesehatan lansia secara mandiri yang dilakukan oleh tim dosen Program Studi Kebidanan Universitas Gunadarma bekerjasama dengan Praktik Bidan Bersama Citra Lestari, Kec. Bojonggede, Kab. Bogor.

Selain itu perlu dilakukan kegiatan penyuluhan kesehatan yang dapat membantu lansia dalam meningkatkan pengetahuannya mengenai Diabetes Melitus, dampak, risiko, serta manajemennya. Juga perlu dilakukan penelitian lebih lanjut, mempublikasikan pada media masa cetak dan membuat karya cipta. Harapannya kegiatan pengabdian kepada masyarakat dapat dilakukan secara berkelanjutan luas bagi masyarakat khususnya di wilayah kerja Praktik Bidan Bersama Citra Lestari, Kec.Bojonggede, Kabupaten Bogor.

\section{KESIMPULAN}

Berdasarkan hasil kegiatan pengabdian kepada masyarakat melalui pemeriksaan gula darah pada lansia bekerjasama dengan Praktik Bidan Bersama Citra Lestari, Kec. Bojonggede, Kab.Bogor, telah dilaksanakan sesuai dengan perencanaan yang telah dibuat tanpa mengalami kendala. Kegiatan dilaksanakan dengan door to door ke rumah masing-masing lansia, dengan menggunakan alat dan bahan yang telah disiapkan. 
Rochmawati, Sri Hayuningsih, Estu Lovita Pembayun, Veronica Fary, Arini Kusmintarti, Liana Elfaristo, Kasyafiya Jayanti, Gracea Petricka, Sisilia Prima

Kegiatan melibatkan 18 orang lanjut usia yang berdomisili di wilayah sekitar tempat Praktik Bidan Bersama Citra Lestari. Kegiatan yang dilakukan dengan door to door ini sebagai salah satu bentuk upaya menjalankan protokol kesehatan dalam rangka pencegahan dan penanganan Covid-19, dengan tetap memakai masker, menjaga jarak aman serta mencuci tangan. Evaluasi dilakukan dengan melihat hasil dari pemeriksaan gula darah yang telah dilakukan. Pemeriksaan kesehatan yang dilakukan pada lansia berkala memberikan dampak yang positif baik bagi lansia secara langsung maupun bagi keluarganya, sehingga dapat melakukan pemantauan terhadap risiko komplikasi maupun adnya kegawatdaruratan. Hal ini menjadi perhatian penting mengingat lansia memiliki faktor risiko yang besar dalam hal kesehatan terutama di tengah pandemi apabila memiliki Diabetes Melitus yang merupakan salah satu komorbid Covid-19.

\section{DAFTAR PUSTAKA}

Kementerian Kesehatan RI. 2018. Riset Kesehatan Dasar 2018. Jakarta.

Kurniawan. Diabetes melitus tipe 2 pada usia lanjut. 2018. Majalah Kedokteran Indonesia. 2018

Ndraha, S. 2017. Diabetes Melitus Tipe 2 dan Tata Laksana Terkini. Departemen Penyakit Dalam Fakultas Kedokteran Universitas Krida Wacana Jakarta, Vol. 27 (2).

Pusat Data dan Informasi Kementerian Kesehatan RI. 2018. Infodatin: Hari Diabetes Sedunia Tahun 2018.

Pusat Data dan Informasi Kementerian Kesehatan RI. 2020. Infodatin: Tetap Produktif, Cegah dan Atasi Diabetes Melitus.

Rosyada A,Trihandini I. 2019. Determinan komplikasi kronik diabetes melitus pada lanjut usia. Jurnal Kesehatan Masyarakat Nasional. 2019;7(9):395-401.

Setiati S, Kuntjoro H, Arya G R. 2019. Proses menua dan implikasi kliniknya. Dalam: Sudoyo AW, Setiyohadi B, Alwi I, K Simadibrata M, Setiadi S, editor (penyunting). Buku ajar ilmu penyakit dalam. Edisi ke-5. Jakarta: Interna Publishing.

Qurratuaeni. 2016. Faktor-faktor yang berhubungan dengan terkendalinya kadar gula darah pada pasien diabetes melitus di rumah sakit umum Pusat Fatmawati. Jakarta. Universitas Islam Negeri Jakarta 